\title{
A escrita dos guaranis nas reduções: usos e funções das formas textuais indígenas - século XVIII
}

\author{
Eduardo Neumann
}

\section{Introdução}

Nas últimas décadas, o interesse em relação aos textos escritos pelos ameríndios levou uma geração de historiadores a repensar a experiência do contato cultural e evidenciar o protagonismo indígena na organização das sociedades hispano-americanas. ${ }^{1}$ Apesar dessa tendência, e da relevância apresentada pela escrita como parte das estratégias de catequese, não há estudos que analisem as apropriaçôes efetuadas por parte dos indígenas da instrução alfabética promovida no Paraguai colonial. No caso das reduções controladas pelos missionários jesuítas, somente os lingüistas haviam sinalizado, pioneiramente, a existência de documentos escritos pelos guaranis. ${ }^{2}$

Ausência que se faz notar, principalmente, diante do fato de que as reduções jesuítico-guaranis configuravam-se, entre os séculos XVII e XVIII, como um espaço social de difusão da cultura escrita. O investimento na alfabetização indígena foi uma decorrência da evangelização pretendida, e cujo aprendizado permitiu aos guaranis atingir uma notável destreza na prática da escrita. Em algumas oportunidades, inclusive, elaboraram obras de caráter devocional - livros, na sua maioria com finalidade litúrgica ou catequética -, participando diretamente na elaboração de vocabulários, catecismos e gramáticas. ${ }^{3}$

Com efeito, as modalidades de evangelização praticadas pelos jesuítas têm permitido compreender a rápida difusão e aceitação do escrito, frente à situação de oralidade primária da sociedade guarani. A partir do impacto da alfabetização na organização social das reduções, nem mais a oralidade, tampouco a "razão gráfica" - a expressão da domesticação do 
pensamento selvagem ${ }^{4}$-, podem ser entendidas sem contemplar as suas interações e influências mútuas. ${ }^{5}$ As implicações presentes na passagem de uma forma de comunicação calcada exclusivamente no uso da voz, como era a sociedade guarani pré-contato, às práticas da escrita no Paraguai colonial já foram contempladas em estudo recente. ${ }^{6}$

Por certo a escrita pode alterar os modos de pensamento e cognição, e por isso é considerada um instrumento da transformação cultural, uma tecnologia profundamente interiorizada. ${ }^{7}$ Contudo, atribuir toda explicação a uma única causa é uma visão equivocada. A introdução da escrita não altera por si só, obrigatoriamente, os padrões sociais de uma cultura. ${ }^{8}$

Neste artigo analisei os usos, as funções e as práticas da escrita indígena nas reduçôes jesuítico-guaranis. Mais precisamente, examinei as maneiras pelas quais os índios apropriaram-se $\mathrm{da}^{9}$ escrita introduzida pelos missionários. Enfim, privilegiei a destreza manifesta pelos guaranis diante da conquista do alfabeto e as finalidades atribuídas ao ato de escrever.

\section{Elite e alfabetização nas reduções}

A instrução alfabética promovida nas reduções, inicialmente voltada aos caciques, proporcionava as condiçôes para que os guaranis elaborassem novas formas de expressão gráfica. Contudo, a escrita serviu, inicialmente, à reprodução do cânone religioso. Por certo, o trabalho letrado executado pelos índios, por muitos anos, foi direcionado para a tradução e adaptação de textos religiosos, mais do que uma atividade propriamente de expressão criativa. ${ }^{10}$ Por meio da prática da "reescritura cristã" ou de tradução, eles foram iniciados na alfabetização em seu idioma, estimulando o exercício de recriação lingüística e estilística. ${ }^{11}$

A partir de situações diferenciadas de contato com o "universo letrado", a escrita foi sendo valorizada e utilizada no espaço reducional, principalmente entre aqueles que faziam parte da "elite" missioneira.

Entretanto, nem todos que integravam este grupo eram alfabetizados. E a elite igualmente não se apresentava de maneira homogênea. Podemos indicar, de maneira geral, uma divisão tripartida, uma tipologia definida por critérios de "recrutamento". O primeiro grupo referia-se a um segmento nativo, hereditário, onde estavam os caciques e seus descendentes. 
A nobreza nativa apresentou papel de destaque nos anos iniciais de vida em redução, recebendo o título de Don. ${ }^{12} \mathrm{O}$ segundo grupo foi escolhido pelos jesuítas. Eles souberam valorizar os indígenas de talento, preferencialmente para as tarefas administrativas. ${ }^{13}$ Ao lado desses dois grupos figurava uma outra elite, estabelecida a partir do mérito religioso e do empenho devocional. Fervor religioso e devoção serviam de critério para definir aqueles que poderiam atuar junto às congregações, espaços voltados para aperfeiçoar a fé cristã e a disciplina religiosa. $\mathrm{O}$ fato de participar de uma congregação também era sinônimo de habilidade com algum instrumento musical. Em geral, estes segmentos apresentavam cruzamentos, sendo comum um indígena estar inserido em mais de um grupo.

Ao mesmo tempo, a habilidade manifesta por alguns guaranis no manuseio das letras credenciou-lhes a exercer o ofício de professores. A instrução alfabética também competia aos maestros de capilla sujeitos encarregados da orientação musical. As atividades de escrita costumavam estar conjugadas com o ensino da música, integrando as artes e os ofícios ministrados nas reduçóes.

De fato, a necessidade social da escrita, inclusive, foi uma realidade pronunciada, determinando que a capacidade alfabética desfrutasse de prestígio e conferisse distinção aos índios letrados. Nesse contexto, a aptidão letrada foi verificada com maior freqüência entre aqueles indígenas que desempenhavam cargos ou funções junto aos cabildos missioneros, modalidade de "conselho municipal" adotada na administração das reduções a partir da aplicação da legislação hispânica para a América, as Leyes de Índias. Entre os integrantes, todos conhecidos como cabildoiguara (cabildantes), há inúmeras manifestações de familiaridade no manejo da pluma. A documentação consultada sinaliza, por exemplo, que a prática da escrita foi mais freqüente entre os mayordomos (administradores de estâncias e armazéns) e os quatiàapoharas (secretários). Igualmente, os testemunhos gráficos indicam que, em algumas oportunidades, escrever mobilizou uma parcela da elite indígena.

Como se percebe, mesmo de forma seletiva, foi facultada aos guaranis acessos à instrução alfabética. Inicialmente como copistas e, posteriormente, como "autores", eles manifestaram um domínio pronunciado da ars scribendi, que estava muito além do simples domínio do abecedário. ${ }^{14}$ 
Diante do convívio com diferentes níveis das práticas de escrita, os indígenas letrados, em determinadas ocasiōes, serviram-se de sua capacidade gráfica de maneiras muitas vezes inesperadas. A capacidade letrada manifesta pelos guaranis indica que há muito por ser feito no que diz respeito à análise do impacto da alfabetização na organização social das reduções.

\section{A escritofilia dos guaranis missioneiros}

Um período excepcional para acompanhar os usos da escrita indígena é o da demarcação de limites, em meados do século XVIII. O Tratado de Madri, assinado em 1750, estabelecia a permuta de sete reduções localizadas na "banda oriental do rio Uruguai" - de um total de 30 -, pertencente à Espanha, a serem entregues a Portugal, em troca da Colônia do Sacramento. A decisão repercutiu de forma acentuada na América meridional, estimulando a comunicação epistolar.

Os trabalhos de demarcação dos novos limites que a execução do referido tratado requeria gerou uma constante correspondência entre os comissários peninsulares, Gomes Freire e o marquês de Valdelírios. Entretanto, a prática da escrita como instrumento de comunicação e negociação política não esteve restrita unicamente aos plenipotenciários ibéricos, sendo igualmente um expediente muito utilizado pelos guaranis missioneiros. ${ }^{15}$ Ocasião na qual houve uma expressiva produção textual indígena, diante da divulgação dos termos presentes no acordo ajustado entre as monarquias ibéricas.

Os testemunhos dessa "reação escriturária" são tanto os papéis apreendidos pelas comissões demarcadoras quanto os demais textos que hoje repousam em alguns arquivos sul-americanos ou europeus (ou seja, documentos dispersos e sem qualquer indexação prévia), bem como as notícias e informes presentes na correspondência de jesuítas que atuavam na região. ${ }^{16} \mathrm{~A}$ novidade dizia respeito à escritofilia indígena - o apego manifesto pelos guaranis à escrita -, resultado de uma expressão gráfica autônoma, sem o controle outrora exercido pelos jesuítas. Essa ruptura marcou a emancipação da escrita indígena nas reduções do Paraguai.

O certo é que os índios missioneiros escreveram com freqüência durante o período de conflito nas reduções orientais, deflagrando a rebeliāo 
indígena conhecida na historiografia como Guerra Guaranítica (175456). Tal constatação tem estimulado indagações quanto às relações históricas estabelecidas pelos guaranis com o passado e o território oriental. A documentação igualmente sinaliza uma discussão pouco referida pela historiografia dedicada ao tema, ou seja, a existência da defesa por escrito daquele que seria o ponto de vista dos indígenas. Em suma: os textos escritos pelos índios missioneiros, e mesmo suas traduções, atualmente, despertam interesse a partir dos aportes da história da cultura escrita.

As interpretações históricas orientadas por essa perspectiva teóricometodológica, com eminente vocação interdisciplinar, têm privilegiado a análise dos usos, funçóes e práticas relacionadas com o escrito. ${ }^{17}$ Os procedimentos metodológicos em questão têm fornecido algumas pistas e subsídios importantes para investigar os materiais escritos e desvendar os significados subjacentes à expressão gráfica. A prioridade é conhecer as distintas intenções que nortearam o ato de escrever e as suas relações com o poder. A escrita é concebida como um conjunto de práticas que podem contribuir para melhor compreender as mudanças e transformaçôes socioculturais em um determinado momento.

Nesse aspecto, a prática da escrita introduziu uma mediação singular entre os distintos protagonistas e, em determinadas ocasiōes, os guaranis alfabetizados manejaram com desenvoltura tal tecnologia. A inserção da elite missioneira em algumas rotinas administrativas do mundo colonial ampliava as suas possibilidades de contato e interação com a sociedade rio-platense. O conjunto de habilidades requeridas no provimento dos cabildos facultava a uma fração da população missioneira, letrada ou não, contato com as práticas burocráticas da monarquia espanhola. ${ }^{18}$ Não podemos pressupor que essa competência alfabética determinasse um distanciamento em relação aos demais indígenas reduzidos, mas criava uma mediação diferenciada com as hierarquias da sociedade e as suas possíveis interaçóes.

Pode-se afirmar que as mudanças verificadas nas maneiras de conduzir as negociações fora o resultado do convívio prolongado dos indígenas com as práticas letradas, sobretudo a partir do século XVIII. A familiaridade manifesta por alguns guaranis com as diferentes formas textuais foi um fator que estimulou novos usos para a competência gráfica indíge- 
na, ampliando as possibilidades de uma relação pessoal e mais direta com o mundo dos textos e permitindo eliminar a atuação dos intermediadores. ${ }^{19}$

Enfim, os indígenas letrados escreveram diversos textos na forma de bilhetes, cartas e memoriais, além de narrativas pessoais. Os documentos redigidos em guarani e, posteriormente, em espanhol, localizados em diferentes arquivos, bibliotecas e coleções, indicam a necessidade de revisar os diagnósticos existentes quanto à difusão da escrita nas reduçôes guaranis nos séculos XVII e XVIII.

\section{As formas textuais da escrita indígena}

A prática da escrita em um momento especialmente dramático, como foi a primeira campanha dos exércitos ibéricos em direção ao território missioneiro em 1754, atingiu níveis elevados. Nas reduções guaranis, a progressiva ampliação do número de sujeitos capazes de registrarem por escrito suas opiniōes também era o resultado da sobreposição de gerações de guaranis alfabetizados. Tal fato favorecia uma modificação nas relações entre os indivíduos e o mundo letrado, cujos reflexos foram visíveis nas rotinas missioneiras. Se, por um lado, agora as lideranças guaranis atribuíram um valor político à escrita, como expressão do autogoverno, por outro a crise deflagrada permitiu registrar a diversificação da produção textual indígena nas reduções.

Por meio dos distintos documentos produzidos pelos guaranis, ainda hoje podemos identificar as características que a escrita adotou nas reduções, visto que eles inventavam novas funções para os modelos culturais compartilhados. Portanto, através das evidências da escrita como os diários, as atas dos cabildos e os memoriais, ainda hoje é possível dimensionar os usos que os indígenas reservaram à capacidade alfabética e a quais demandas respondia.

As experiências de contato intercultural, vividas principalmente durante o conturbado ano de 1754 , intensificaram por parte de alguns representantes da elite missioneira o interesse em registrar os acontecimentos protagonizados ou vivenciados como testemunhas. A disposição em escrever foi surpreendente, tanto pelo aspecto quantitativo como pelo qualitativo desses textos. A multiplicação dos escritos, à época, permite 
explorar as modalidades que a produção textual indígena atingiu nas reduçôes. A intensificação das negociações conferia a cada encontro novas perspectivas. Os momentos excepcionais foram avaliados como dignos de audiências mais amplas e mesmo distantes. Motivo pelo qual foram vertidos para o papel por sua relevância no destino das reduções.

Em geral, os textos produzidos pelos guaranis foram associados ao trabalho executado pelos secretários ${ }^{20}$ ou por algum indígena letrado vinculado às atividades cabildantes. Afinal, os indivíduos apresentam níveis diferenciados de domínio da capacidade gráfica. Em determinadas ocasióes alguns fizeram uso de suas habilidades "escriturárias", principalmente por meio da redação de cartas ou informes ao governador de Buenos Aires.

Por certo, entre os guaranis letrados de uma redução, os secretários, em decorrência do seu ofício, estavam sujeitos a um convívio mais próximo com os instrumentos de escrita. Em determinados momentos - estimulados por novos acontecimentos - alguns quatiàapoharas aproveitaram a quebra de protocolos, como foram as viagens acompanhando a milícia missioneira, para dar vazão aos seus ímpetos letrados. A competência gráfica desses indígenas, por exemplo, se fez latente nos momentos de estranhamento com os lusitanos. A percepção aguçada do contexto no qual estava inserido, aliada à longa expectativa, provavelmente estimulou o registro diário da jornada rumo a uma das margens do rio da Prata, no início do século XVIII.

Ao começar a escrever, o escrivão demonstra cuidado com o registro dos dados e informações da expedição de que participava. A transcrição do parágrafo inicial do diário é esclarecedora: "El Año de 1704. A 1 de septiembre, la gente de Hábeas salió de su propio pueblo yendo a la guerra. El 12 de septiembre se juntaron con todos los de los otros pueblos en el Aguapié Miri en frente de San Carlos." ${ }^{21} \mathrm{O}$ relato lança mão da temporalidade ocidental, pois o escrivão indica o dia, o mês e o ano da saída da redução de Corpus, informaçôes que sinalizam que o diário foi lavrado in situ, procurando captar a dinâmica dos acontecimentos enquanto transcorriam.

Sem dúvida, a redação de um diário é uma evidência da preocupação dos guaranis em forjar um registro dos dias agitados, conturbados. Por sua vez, a disposição material, na forma de um livro, sinaliza uma intencionalidade claramente vinculada à preservação do texto. Os episódios 
narrados foram valorados como dignos de memória. A função social da escrita, em ocasiōes de contato com o "inimigo histórico", como foram os portugueses, ao que parece era a de operar como instrumento de conservação de experiências passadas consideradas decisivas para a coletividade.

Afinal, escrever era um modo de participar, de atuar nos assuntos mais candentes. $\mathrm{O}$ rigor ou ênfase dedicados a um determinado tema poderia servir de indício da condição sociocultural do redator. Foi o caso de Primo Ybarenda, então servidor na redução de São Miguel e futuro secretário. Em setembro de 1753 ele resenhou alguns fatos em tom de indagação e remeteu a epístola ao governador de Buenos Aires, José de Andonaegui. ${ }^{22}$ A carta, ao contrário do que se poderia imaginar, não foi escrita para manifestar contrariedade às ordens de transmigração, e sim para informar a perplexidade de uma parcela da população diante do impasse que estavam enfrentando. A capacidade gráfica indígena nas reduções, nesse momento, externava sinais de um distanciamento do cânone religioso, momento em que diferentes gêneros textuais foram elaborados pelos guaranis.

A análise conjunta do corpus documental sinaliza que houve diferentes formas de apropriações da escrita nas reduções. Nesse sentido, por vezes, os guaranis, ao julgarem um determinado momento como digno de registro, recorreram às suas competências alfabéticas para produzir um relato. Documentos que atualmente permitem reconhecer o protagonismo indígena nas reduções e, principalmente, nos conflitos demarcatórios.

Entre os textos indígenas missioneiros, há uma evidente preponderância do gênero epistolar; ${ }^{23}$ tanto de cartas oficiais como aquelas de caráter político-administrativo. As cartas figuram como a modalidade textual mais acionada pelos guaranis letrados para tornarem públicas suas demandas. Igualmente há os bilhetes, uma variante dessa modalidade de comunicação escrita - recorrente em alguns episódios -, mas que não está pautada pelas mesmas regras da epistolografia culta.

Entre os guaranis, a escrita epistolar desempenhou a função de contatar a administração colonial, sendo instrumento diplomático de reivindicação e protesto, voltada prioritariamente para as relações externas, como meio de comunicação. Nesse aspecto, as correspondências indígenas foram dirigidas em três direções: as autoridades hispânicas, no caso os comissários demarcadores e o governador de Buenos Aires; como instru- 
mento de comunicação entre guaranis e jesuítas; e como veículo de contato pessoal entre indígenas.

Os bilhetes, por sua vez, estavam direcionados para a comunicação entre os próprios indígenas, sempre redigidos em língua guarani, indicando uma circulação mais reservada. Aqueles que aparecem traduzidos para o castelhano referem-se a comunicaçóes entre lideranças de caráter pragmático e disseminam opiniōes comuns sobre mobilização de soldados de guerra.

Nas reduções guaranis, as cartas serviram para diversas finalidades, como manifestar desacordo, expressar insatisfações, enviar um conselho ou, como foi recorrente, convocar homens para a guerra. Tais textos poderiam adquirir várias formas, e atingiram níveis elevados de expressão gráfica nas reduções. Felizmente, ainda remanescem nos arquivos algumas provas dessa prática de escrita indígena. Esses textos, em boa parte, estão voltados para as demandas oficiais, e são os que apresentaram maiores possibilidades de conservação, comparados àqueles de caráter pessoal.

Em resumo: primeiro foram os bilhetes e as cartas, posteriormente os textos mais longos na forma de relatos, alguns próximos aos de uma crônica pessoal. As cartas, cujas mensagens estavam centradas principalmente na comunicação oficial, foram o ponto de partida para outras modalidades de textos indígenas voltados a registrar experiências de caráter pessoal ou coletivo. 


\begin{tabular}{|c|c|c|}
\hline Relato pessoal & $\begin{array}{l}\text { Procura estabelecer uma } \\
\text { memória de determina- } \\
\text { dos fatos vivenciados co- } \\
\text { letivamente. }\end{array}$ & $\begin{array}{l}\text { Textos com essa característi- } \\
\text { ca são raros, a relação de Ne- } \\
\text { renda é o principal exemplar } \\
\text { conhecido. Há uma carta de } \\
\text { Primo Ybarenda que pode ser } \\
\text { enquadrada nesse gênero. } \\
\text { Ambos os textos correspon- } \\
\text { dem ao período de conflito } \\
\text { nas reduções. }\end{array}$ \\
\hline Atas de cabildo & $\begin{array}{l}\text { Anotações resumidas dos } \\
\text { temas tratados nas ses- } \\
\text { sões dos cabildos. Algumas } \\
\text { atas apresentam caracterís- } \\
\text { ticas de uma resenha "his- } \\
\text { tórica". }\end{array}$ & $\begin{array}{l}\text { São consideradas tardias nas } \\
\text { reduções e existem informa- } \\
\text { ções apenas para a segunda } \\
\text { metade do século XVIII. }\end{array}$ \\
\hline $\begin{array}{l}\text { Escrita exposta: cru- } \\
\text { zes, cartazes, lápides }\end{array}$ & $\begin{array}{l}\text { Modalidade voltada pa- } \\
\text { ra a comunicação pública } \\
\text { utilizada em espaço aber- } \\
\text { to, visando a uma leitura } \\
\text { a distância }\end{array}$ & $\begin{array}{l}\text { Recurso utilizado pelos jesu- } \\
\text { ítas no início da catequese. } \\
\text { Foi apropriada pelos guara- } \\
\text { nis para demarcar território, } \\
\text { servindo de suporte a men- } \\
\text { sagens com caráter de ulti- } \\
\text { mato. }\end{array}$ \\
\hline Narrativa histórica & $\begin{array}{l}\text { Textos narrativos volta- } \\
\text { dos para a compilação de } \\
\text { fatos transcorridos nas re- } \\
\text { duçōes. Tais registros fo- } \\
\text { ram ordenados cronolo- } \\
\text { gicamente. }\end{array}$ & $\begin{array}{l}\text { Obras dadas como perdidas. } \\
\text { Há apenas referências por } \\
\text { intermédio de outros auto- } \\
\text { res, que tiveram oportuni- } \\
\text { dade de ler estes textos. }\end{array}$ \\
\hline & Imimicsoces pesso & \\
\hline
\end{tabular}

chivo Histórico Nacional / Madrid; Arquivo General de Simancas / Valladolid; Archivo General de Indias / Sevilla; Real Academia de la Historia / Madrid. 


\section{A escrita dos mayordomos}

A escrita, ao extravasar os âmbitos tradicionalmente reservados a ela, como eram os espaços destinados ao ensino das primeiras letras e os cabildos, criava as condições para que a educação gráfica fosse praticada por indivíduos que, mesmo inseridos no mundo das letras, nem sempre fizeram um uso mais amplo da instrução alfabética recebida. Ao que parece, foram nos períodos de maior proximidade, ou mesmo de contato com os funcionários encarregados da demarcação, que alguns guaranis ultrapassaram os usos tradicionalmente reservados à escrita nas reduçôes. Ocasiōes em que mantiveram uma relação mais pessoal com o texto, principalmente para estabelecer um relato, uma memória indígena dos momentos atípicos verificados durante a execução dos trabalhos demarcatórios. Há inúmeras provas de quanto os guaranis alfabetizados sentiram-se atraídos pela idéia de produzir relatos ou deixar mensagens. Ao que parece, nem sempre encontravam os meios necessários à escrita, como papel e tinta, motivo pelo qual, em determinadas ocasiōes, deixaram inscrições afixadas em pedaços de couro ou tábuas.

Sem dúvida, a mudança mais significativa verificada no período de conflito nas reduçôes foi que a escrita deixou de ser um atributo exclusivo ou restrito aos secretários. Diversos guaranis letrados manifestaram qualidades semelhantes às dos escrivães, principalmente os indígenas com passagem ou cargo nos cabildos missioneiros, ou seja, os indivíduos que foram preparados para as tarefas administrativas. Muitos demonstravam preocupação com o que estava sendo informado e negociado por escrito.

A capacidade de expressar-se por meio da escrita, recorrendo às formas textuais conhecidas, também foi manifesta com certa freqüência por parte dos mayordomos (administradores). A incidência da escrita entre aqueles sujeitos que desempenhavam funções vinculadas aos cabildos mas provavelmente sem participar das decisões - sugere vínculos entre competência alfabética e o desempenho de um determinado cargo.

Com efeito, as atividades desempenhadas como fiscais de armazéns e no controle de recursos humanos permitem formular um questionamento sobre as conexôes existentes entre os sujeitos que fizeram uso assíduo de suas capacidades letradas e os ofícios exercidos nas reduções. Aos 
mayordomos competia o cuidado dos bens da comunidade e, para tanto, "como auxiliares suyos habia indios contadores, fiscales, y almaceneros", como foi registrado na Real Cédula de 1743 . Em outras palavras, a prática da escrita estava vinculada ao exercício de uma função ou cargo na administração missioneira, caso dos indígenas que controlavam os depósitos e armazéns de mercadorias nas reduções.

Por certo, devido às suas atribuições junto aos cabildos, os mayordomos recorreram com freqüência à sua capacidade alfabética, principalmente nos momentos de contabilidade. Segundo Rafael Carbonell, o nível de profissionalismo que demandava as funçôes de mayordomo implicava que o "novo electo contaría con el asesoramiento del mayordomo saliente para llevar bien el control de productos y mercaderías". ${ }^{24}$ Assim, conforme esse mesmo autor, a partir de 1732, a permanência nesse cargo não poderia reincidir nas mesmas pessoas por um período superior a quatro anos. Tal medida visava evitar enraizamentos e o exercício despótico dessas funções.

Os mayordomos, diante da necessidade de acompanhar e controlar a produção, desempenhavam a função de administradores e, ao que tudo indica, mantinham contato escrito com seus subordinados e posteriormente informavam os respectivos cabildos das condiçóes e dos bens da coletividade. Com certeza anotavam em cadernos os produtos extraídos das chácaras e estâncias, controlando o que seria estocado nos armazéns missioneiros. Por meio do estudo de Teresa Blumers, dedicado ao sistema de registros contábeis nas reduçóes, somos informados de que entre os diversos livros utilizados em cada redução figurava um "Libro de procuradores y estancias". ${ }^{25}$

Portanto, o exercício da contabilidade requerida no desempenho das atividades facultou aos procuradores responsáveis por cada redução um contato freqüente com o "mundo sobre papel". O exercício de anotar a produção agrária e pecuária, bem como controlar os indígenas recrutados para tarefas diversas, habilitou os mayordomos no ordenamento por escrito de fatos, dados e nomes. Tal conhecimento lhes facilitou o gerenciamento dos recursos humanos no momento de aproximação dos exércitos ibéricos.

Nesse sentido, a prática da escrita permitiu aos mayordomos contato freqüente com os demais guaranis letrados. Entre os indígenas recrutados 
por talento nas reduções, estes foram assíduos escreventes à época do conflito. Na documentação consultada, encontrei evidências da atuação desses sujeitos, principalmente por destinarem à escrita uma finalidade distinta da habitual. São os escritos desse segmento letrado que apresentam temas e, inclusive, abordagens novas da realidade.

\section{Os papéis apreendidos de Paracatu}

O conjunto de documentos apreendidos em outubro de 1754, após a Batalha do Daymal - um confronto travado entre uma milícia indígena e o exército a serviço da Espanha -, permite comprovar a capacidade gráfica de um segmento da elite letrada missioneira. Os papéis apreendidos com Rafael Paracatu, cacique na redução de Yapeyu, são na sua maioria respostas enviadas a ele pelos mayordomos que controlavam as estâncias. ${ }^{26}$ A capacidade gráfica desses índios permitiu ao cacique Paracatu manter contato assíduo com eles e, assim, coordenar temporariamente a oposição indígena nas reduções. Por meio desses papéis tomamos conhecimento do conteúdo de documentos singulares a respeito dos usos internos reservados à escrita pelos guaranis.

A redução de Yapeyu foi uma das mais convulsionadas, principalmente diante da presença do exército espanhol em suas terras. Procurando obstruir a marcha das tropas hispânicas por suas estâncias, o cacique Paracatu e os integrantes do cabildo recorreram à escrita como meio de contato destinado a agilizar a comunicação e gerir ações conjuntas. Os papéis apreendidos com Paracatu sinalizam, primeiro, a preocupação das lideranças em responder aos pleitos formulados por seus companheiros. E, em segundo, revelam a rapidez em atender, no mesmo dia, aos pedidos e às consultas feitas. Tais cuidados visavam manter os indígenas informados a respeito da movimentação dos exércitos ibéricos, notícias que bem administradas poderiam ampliar as possibilidades de êxito da oposição missioneira.

Nessas ocasiões os indígenas rebelados mantinham-se informados por meio da comunicação escrita a respeito dos movimentos dos espanhóis na região. Como a estância de Yapeyu era muito extensa, os mayordomos foram constantemente contatados e instruídos, bem como forneciam informes freqüentes a Paracatu. 
Algumas dessas correspondências, inclusive, foram coletivas, constando, ao final, a expressão "todos los mayordomos te escrivimos". Como a de agosto de 1754, reproduzida abaixo:

Dn Raphael Paracatu. Dios te guarde te decimos, nosotros los Mayordomos. Há llegado a nosotros el papel, tenemos confianza em Dios como tu, y te quedamos agradecidos. Dios nos preserbe de todo mal, y quiera que vivamos em el camino de los Santos Sacramentos, y que andeis solo em el amor de Dios. Jesús Christo nos manda por su amor, y nosotros por el nuestro, y esto has de tener siempre ante los otros, y has de pedir a la Virgen Santissima nos de toda felicidad y pidamos tambien a las Santas Almas que estan delante de Dios, que pidan para nossotros fortaleza y que nos ayude. Esto te escrivimos para que em nombre de Dios lo leas. Joseph Aviare te llevo dos aspas de Polbora, y 44: balas, 7: pliegos de papel blanco, en un canuto de taquara, cinco tercios, y uma volsa de tavaco, y como no savemos en que paro esto, no te escrivimos mas que por que lo sepas, y quien fué el portador te avisamos. Dios te guarde te decimos. 6 de Agosto de 54: anos, unos pobres como tu, que te aman: todos los Mayordomos te escrivimos. ${ }^{27}$

Como se pode verificar, a escrita atuou como canal de comunicação entre aqueles guaranis empenhados na oposição à presença hispânica, atualizando as principais lideranças, e comunicando a determinação dos administradores em seguir resistindo. Pela relação dos mantimentos enviados pelos mayordomos é possível inferir a importância que o contato in scriptis desempenhou nessa ocasião, pois na resposta enviada a Paracatu foi mencionado o envio de "pliegos de papel blanco", matéria-prima destinada a dar continuidade à troca de informações por escrito.

Através das mensagens enviadas a Paracatu somos informados de que as respostas eram imediatas, provavelmente pelo caráter diligente que os guaranis sublevados atribuíam ao informe escrito. Algumas cartas, por exemplo, foram respondidas no mesmo dia em que chegaram aos destinatários. Pelo conjunto das correspondências guaranis foi possível constatar a urgência da escrita e uma preocupação com a rápida resposta, como parte das estratégias de guerra. Em determinados contatos os guaranis agregavam às suas missivas expressóes como "invieis la respuesta a esta carta", que são indícios da importância atribuída à escrita nas negociações polí- 
ticas dos índios letrados com os seus interlocutores, fossem eles companheiros de redução, demarcadores ou qualquer outra autoridade.

Enfim, por meio desses textos, alguns mayordomos têm saído do anonimato exatamente pelo fato de terem deixado testemunhos escritos de suas opiniōes, quando participaram ativamente nos bastidores do conflito, promovendo usos inesperados de suas competências gráficas. Exemplos possíveis da escritofilia guarani são os textos de Chrisanto Nerenda, Pasqual Yaguapo e Valentin Ybariguá. Documentos redigidos quando desempenhavam, em meados do século XVIII, as funções de administradores de suas reduçôes. Ao tomarem o texto epistolar como modelo, desenvolveram formas de expressão voltadas a registrar suas opiniōes ou intervir no rumo dos acontecimentos.

\section{A relação de Chrisanto Nerenda: escrita e memória}

O relato de Chrisanto Nerenda, mayordomo na redução de São Luís e integrante da congregação de São Miguel, sem dúvida configura-se no texto indígena que melhor sintetizou o estranhamento missioneiro em relação ao mundo extra-reducional, especialmente a conduta dos portugueses. Após ser capturado em Rio Pardo e passar alguns meses em cativeiro, Nerenda, quando regressou a São Luís, redigiu uma extensa relação, em língua guarani, narrando os episódios que havia presenciado. Sua relação corresponde ao momento de sua chegada ao fortim lusitano - acompanhado de meia centena de companheiros - nas margens do rio Jacuí, até o retorno à sua redução de origem. ${ }^{28}$

Com efeito, quase sem exceções, a escrita pessoal é marcada pelas experiências, por vezes traumáticas, sobretudo relacionadas a contextos excepcionais, ameaças ou perseguições. Situaçóes como estas rompiam com a rotina da vida em redução, atuando como estímulo à elaboração de um registro da sobrevivência do narrador.

Por meio da narrativa de Nerenda sabemos que ele passou por situações extremas devido a ameaças e privações. Durante aproximadamente dois meses, entre o início de maio até meados de julho de 1754, o administrador da redução de São Luís foi submetido a várias pressões e conheceu pessoalmente Gomes Freire. Em mais de uma ocasião foi interrogado 
sobre o modus vivendi dos jesuítas, sem jamais sucumbir às ameaças recebidas. Esse guarani letrado, de aproximadamente 40 anos, foi um dos 14 sobreviventes a que Freire concedeu liberdade, depois de sua prolongada permanência na vila de Rio Grande.

Em meados do século XVIII, o relato elaborado por Nerenda chegou a atingir grande repercussão no âmbito missioneiro, a se julgar pelas informações históricas sobre a circulação do texto. Em 1758, o ex-provincial do Paraguai, Manuel Quirino, ao elaborar um manuscrito compilatório dos principais episódios relacionados com o Tratado de Madri, qualificou Nerenda como "índio historiador". ${ }^{29}$ Tal apreciação decorre da narrativa minuciosa elaborada pelo mayordomo de São Luís a respeito do período em que ele permaneceu prisioneiro.

Em meio à expressiva produção de cartas oficiais, com eminente caráter político-administrativo, e de comunicação pessoal, por meio de bilhetes, alguns guaranis aventuraram-se em uma escrita com características de um relato pessoal e, possivelmente, de um registro da "memória social". Foi, justamente o fato de os conteúdos da Relación de lo que sucedió a 53 Indios del Uruguay estarem de acordo com a óptica pretendida pelos jesuítas, ou seja, a defesa do modo de vida cristão, que determinou a tradução e conservação do texto à época.

Contudo, Nerenda recorreu à escrita para registrar sua posição pessoal, no caso o estranhamento em relação ao modo de vida dos portugueses. Dessa forma, manifestava sua adesão ao projeto missional - e não o tradicional repúdio aos trabalhos de transmigração, expresso em outros escritos indígenas do mesmo período. Inclusive pelo fato de ser congregante, o relato de Nerenda expressa inquietação de um indivíduo devoto. Ele tanto fazia parte da elite recrutada por mérito religioso como, igualmente, ocupava um cargo ligado ao cabildo por sua aptidão letrada (administrador de estância).

Entre os escritos pessoais, figuram textos que foram motivados pelo desejo de formular testemunhos, e assim manifestar opiniōes que poderiam atingir outras platéias. Por certo, Nerenda escreveu movido pela expectativa de ser lido por outros, pelo exercício do seu ofício, quando direcionou sua habilidade para a elaboração de um texto com características de memória pessoal. $\mathrm{O}$ exercício da escrita de maneira freqüente favore- 
ceu o desenvolvimento de outras formas textuais, documentos que funcionam como suportes para recordações, depositários de lembranças. Antonio Castillo, ao comentar as motivaçóes presentes ao ato de escrever, destacou o fato de esse exercício nem sempre corresponder exclusivamente ao apreço individual, pois apesar de conformar "[...] el espacio escrito cuna de la intimidad (privacy), pero igualmente explicitan la conciencia histórica del sujeto, su postura ante los aconteceres externos y el lugar de éstos en el orden de la memoria personal'. ${ }^{30}$

Nesse sentido, a escrita, em alguns episódios, foi depositária de alteridades geradas diante de experiências singulares. Por seu conteúdo, a relação de Nerenda apresenta elementos que a aproximam de uma memória coletiva, pois é uma forma de escrita pessoal mais centrada no exterior. Segundo James Amelang, a característica de narrativas dessa natureza é que sua "mirada se dirige hacia fuera, no hacia dentro". ${ }^{31}$

Como vimos, a "razão gráfica" nas reduções atendia a propósitos variados. Entretanto, nessa época de conflitos ela também poderia expressar, sem dúvida, uma preocupação com a longevidade dos acontecimentos. Assim, atuava como um remédio contra o esquecimento, um antídoto para minimizar a amnésia social. Em certo sentido, escrever havia assumido entre a elite missioneira, e mesmo junto aos índios letrados, a condição de um testemunho que imaginavam não seria superado facilmente.

A escrita pessoal, entre outros textos produzidos nas reduções, permite afirmar que a memória social foi relevante no cotidiano missioneiro e nos rumos da vida em redução. Afinal, os guaranis vivenciaram acontecimentos excepcionais, justificando o interesse por preservá-los, para não serem relegados ao esquecimento. Outros indígenas, por sua condição de lideranças, igualmente recorreram à escrita por acreditarem que por meio desse procedimento poderiam interferir no rumo dos acontecimentos.

\section{As instruções escritas de Pasqual Yaguapo}

As cartas redigidas por Pasqual Yaguapo, liderança guarani de destacada atuação durante o período de conflito nas reduções, demonstra quanto a escrita também foi um expediente voltado à instrução coletiva, no caso uma tentativa de organizar a tropa missioneira. Quando as comissóes 
demarcadoras chegaram ao território implicado na permuta, este indígena letrado ocupava a função de alcaide maior da redução de São Miguel. Nessa ocasião, escreveu uma carta conjunta com o corregedor miguelista, Pasqual Tirapare, informando ao padre Tadeu Henis dos distúrbios na estância de Santo Antônio. ${ }^{32}$

Tudo indica que, nesses anos de rebelião, os índios passaram a designar de maneira autônoma os ocupantes dos ofícios junto aos cabildos missioneiros, definindo a partir de uma lógica própria, o provimento dessas funções. Assim, Yaguapo passou a desempenhar as funções de mayordomo, ofício que lhe permitia acompanhar de perto a mobilização indígena nas estâncias e nas demais áreas rurais.

Por meio de procedimentos escritos, a elite missioneira procurou orientar os soldados missioneiros sobre a melhor conduta a ser adotada no momento de contato com os funcionários encarregados da demarcação. Em mais de uma ocasião Pasqual Yaguapo valeu-se da sua condição de administrador da redução de São Miguel e elaborou instruções que deveriam ser repassadas aos demais guaranis. Em outubro de 1754, Yaguapo escreveu uma carta ao tenente Miguel Arayecha na qual informa claramente os motivos do envio dessa missiva: "os escriviremos y tambien los caziques del Pueblo, tambien encargamos que no se dejen engañar".

Nessa ocasião, Yaguapo, inclusive, aproveitou para alertar o seguinte:

[...] cuando dijere que benga un Casique à hablarnos no salga de la muchedumbre de los soldados para que con sus muchas palabras los han de engañar, con dadivas, con un calzon, con un sombrero, con una chupa, o con alguna casaca, o haziendoles oyr varias cosas y entonces han de fraguar Pleito contra nosotros por todas partes. ${ }^{33}$

Por sua condição de administrador e, principalmente, seu envolvimento na mobilização missioneira, Yaguapo vislumbrou na escrita um recurso capaz de instruir as tropas e, desse modo, evitar que fossem facilmente ludibriadas. A credibilidade atribuída à escrita como instrumento capaz de promover uma ação conjunta ficaria bastante evidente em outro texto escrito pelo mesmo indígena.

Em junho de 1755, ele redigiu um arrazoado de motivos intitulado "Para los Indios que han de avistarse con los Españoles, les pongo a la vista 
lo que han de decir los Indios, para que lo oigan todos los Caziques y Cavildos". ${ }^{34} \mathrm{O}$ conteúdo dessa mensagem está marcado por um forte didatismo que procura, através de um diálogo ficcional, voltado a fornecer aos indígenas argumentos de oposição à passagem do exército espanhol por terras missioneiras. $\mathrm{O}$ texto, na forma de um manifesto, intercalado com um diálogo hipotético, visava instruir os guaranis que estavam nas estâncias quanto aos argumentos que deveriam verbalizar caso encontrassem as comissōes demarcadoras.

Por seu conteúdo, o texto de Yaguapo muito provavelmente foi concebido com a finalidade de leitura coletiva, servindo de instrução geral a toda a população, inclusive a caciques e cabildantes. A leitura dessa instrução visava à memorização dos argumentos apresentados, pois a população missioneira estava familiarizada com a leitura oralizada. Vale recordar que, durante muito tempo, as informaçôes apenas eram disponibilizadas aos guaranis através da leitura em voz alta, e os indígenas, diante do treinamento recebido, apresentavam grande facilidade para fixarem os conteúdos apresentados verbalmente. Pode-se dizer que a memória indígena foi "treinada" inicialmente pela voz, depois pela escrita, ao longo de décadas de vida em redução.

No final da instrução, Yaguapo aproveitou o espaço em branco para escrever uma breve mensagem ao corregedor da redução de São Miguel, Joseph Tiarayu, o Sepé. Nela informava sobre um encontro que estava para celebrar-se entre o marquês de Valdelírios e o governador de Buenos Aires, José de Andonaegui.

Essa entrevista, segundo sua avaliação, deveria resultar em algo novo. Afinal, as lideranças guaranis estavam atentas a todas as negociaçōes mantidas entre as autoridades ibéricas e utilizavam a escrita como veículo de atualização constante sobre as transações, exatamente para anteciparemse às decisões que estavam sendo tramadas, procurando com este procedimento obter algum tipo de vantagem quanto ao conhecimento das açôes de seus potenciais oponentes.

\section{As cartas de Valentin Ybariguá}

Entre os papéis divulgados à época do conflito, alguns foram alvo de sérias dúvidas quanto à autoria indígena, como no caso de uma carta es- 
crita por Valentin Ybariguá. Contudo, podemos afirmar que ele ocupava o cargo de mayordomo na redução de São Miguel e era membro de uma das suas principais famílias. ${ }^{35}$ A carta, datada de 5 de fevereiro de 1756, estava dirigida à principal liderança guarani na redução de São Miguel: Sepé Tiarayu.

A mensagem, no seu conteúdo, transparece a preocupação dos indígenas rebelados com a atualidade das notícias. Efetivamente, o texto é um registro dos dias agitados que antecederam o grande conflito registrado em território missioneiro, no dia 10 de fevereiro, conhecido na historiografia como Batalha de Caiboaté.

O certo é que a carta de Ybariguá conseguiu chegar a seu destinatário, pois ela foi encontrada na algibeira do corregedor de São Miguel, Sepé Tiarayu, morto no dia 7 de fevereiro, no confronto com uma milícia hispânica. Inclusive foi essa carta que permitiu ao governador de Montevidéu, José Joaquim Viana, certificar-se quanto à identidade de Sepé.

Em sua mensagem, Ybariguá solicitava rapidez no repasse de informações e acrescentava as seguintes recomendaçôes: "Se os ditos vos mandarem alguma carta, despachai-a imediatamente ao Padre Cura [...]" e agregava ao final que em caso de necessidade "[...] escriban inmediatamente, y que todos los dias escriban lo que hubiere de novo sin falta". ${ }^{36} \mathrm{~A}$ importância conferida à escrita, e como esta foi utilizada pelos mayordomos, é evidente.

As cartas de Ybariguá permitem demonstrar as diferentes finalidades atribuídas pela elite indígena à escrita no transcurso de uma década. Sabemos que o letrado em questão recorreu novamente à sua competência alfabética, precisamente na época da expulsão da Companhia de Jesus dos domínios hispano-americanos, em 1768. Tais escritos permitem especular a respeito dos usos que os indígenas destinaram à escrita, por ocasião da saída dos jesuítas da Província do Paraguai. Nessa ocasiāo, Ybariguá redigiu duas breves missivas. Uma delas estava dirigida ao governador interino das missóes orientais, Francisco Bruno de Zabala, e a outra ao governador de Buenos Aires, Francisco de Paula Bucareli.

A primeira, com data de 12 de agosto de 1768, dirigida a Zavala, saudava a chegada dos novos religiosos (Pa'í), recém-indicados para ocupar as funções espirituais anteriormente exercidas pelos jesuítas: 
Gracias decimos a Dios (Tupä y al Santo Rey que nosotros los Pay (Pa’i) vemos en sus buenas obras así como en su santidad, en todo.

Celebramos y nos congratulamos, Dios (Tupä) ciertamente los trajo a nosotros, decimos nosotros todos los de San Miguel. Esto que se descubre es lo que te escribimos brevemente de corazón. Que Dios (Tupä), nuestro dueño, os guarde ahora y por siempre. ${ }^{37}$

No dia seguinte, portanto 13 de agosto, o mesmo Ybariguá escreveu da redução uma outra carta a Bucareli, em que roga:

Le pedimos que nos dé estos 338 caballos que tenemos (usamos), porque nosotros quienes alimentamos a los siervos del Rey, precisamos del caballo para tomar la vaca simarron, e incluso necesitamos de otros caballos, comprendemos uma vez más, danoslo (por favor), Señor Gobernador en nombre del santo Rey, solamente por esto te escribimos nosotros los (del) cabildo de San Miguel y los Caciques, em hora buena, Dios te guarde. ${ }^{38}$

Sabemos que o referido indígena tinha plena noção das atribuições políticas de Bucareli e de Zavala, posto que manteve contato direto com essas autoridades quando participou, no dia 30 de julho, da Compulsa de los Autos originales de el Pueblo de San Miguel. ${ }^{39} \mathrm{O}$ conhecimento das respectivas alçadas de poder que cada autoridade representava resultou no envio de mensagens diferenciadas a cada um. Quanto ao pedido de cavalos e à maneira como este o encaminhou, transparece uma prática de registros relacionada ao controle das estâncias, ou seja, a escrita praticada pelos mayordomos, atividade desempenhada anteriormente por Ybariguá.

Por meio dessas mensagens, ao que parece, este guarani letrado procurou conduzir a nova situação de maneira a influenciar a decisão dos novos administradores. Motivo pelo qual tratou primeiro em saudar, por intermédio de Francisco Zavala, a chegada dos novos religiosos às reduçôes, para então depois enviar ao governador de Buenos Aires o pedido dos cavalos. O texto, sem dúvida, é adulatório. Tudo indica que possuía como escopo preparar o caminho para a solicitação do dia seguinte. Portanto, além do caráter estratégico da redação das duas cartas, deve-se destacar a competência gráfica desse guarani, que o autorizava a barganhar diretamente com as autoridades coloniais.

Para compreender melhor as motivações que levaram Valentin Ybariguá a escrever as duas missivas reproduzidas acima, é importante recor- 
dar que ele esteve envolvido na oposição indígena ao Tratado de Limites e ocupava, à época, o cargo de mayordomo.

Em 1768, ele desempenhava o cargo de tenente e recorreu à escrita para expressar sua posição favorável às mudanças, procurando, ao que tudo indica, dissipar qualquer dúvida quanto à sua adesão à nova administração. É de supor que as recordações dos conflitos passados - quando houve intensa mobilização dos guaranis em São Miguel -, aliadas ao desfecho trágico em Caiboaté, tenham influenciado na adoção de uma atitude colaboracionista, procurando evitar qualquer tipo de confrontação.

Como ele conhecia os protocolos que regiam a escrita de caráter oficial, procurou fazer uso deles exibindo os recursos simbólicos que acumulara. Mesmo em um texto breve, foram respeitados os procedimentos necessários a esse tipo de correspondência, com a indicação clara do destinatário, a saudação de abertura, a informação principal, seguida do encerramento e da assinatura. Por sua formação letrada, Ybariguá dominava as convenções que regem a epistolografia, como demonstrou em sua correspondência com as novas autoridades hispânicas. E, possivelmente, ele avaliou que ao expor sua adesão às diretrizes fixadas por Bucareli poderia, assim, estabelecer uma relação positiva com a nova administração colonial. Igualmente, a saída dos jesuítas abria um espaço para a promoção pessoal, o que pode também ter influenciado a decisão de Ybariguá de manifestar-se por escrito.

O certo é que, a partir da expulsão dos jesuítas, houve uma profusão de textos indígenas escritos em guarani e espanhol, momento no qual buscavam interlocução direta com as autoridades provinciais, atuando dentro do legalismo das normas administrativas do Império Espanhol.

\section{A título de conclusão}

Os usos reservados à escrita pelos guaranis letrados, em um contexto de conflito, tanto expressa um desejo de comunicação quanto foi uma forma de participar aos demais companheiros suas experiências ou preservar as efemérides nas quais estiveram envolvidos. A elite missioneira utilizou a escrita para transmitir informações, estabelecer negociações e também para fazer de suas experiências um exemplo para os demais. $\mathrm{O}$ 
interesse indígena em deixar registros de suas opiniōes e inquietações demonstra quanto a escrita e a memória estavam imbricadas no cotidiano da população missioneira, como partes de um jogo social no qual escrita e poder também se apresentavam entrelaçados.

Com efeito, se, por um lado, a comunicação in scriptis mantinha as principais lideranças informadas a respeito dos acontecimentos recentes, por outro cumpria a função de veicular uma versão indígena diante dos rumores que circulavam na região implicada no Tratado de Madri. Motivo pelo qual os contatos epistolares foram muito valorizados pelos guaranis, revelando como a escrita tomou conta das relaçôes estabelecidas pelos índios letrados com os seus interlocutores, fossem eles companheiros de redução, demarcadores ou qualquer outra autoridade.

As pesquisas históricas realizadas nos últimos anos a respeito da organização social estabelecidas nas reduções guaranis têm apresentado resultados inovadores frente às interpretações tradicionais e apologéticas comumente difundidas do passado missioneiro. Alguns dos exemplos apresentados nesse artigo visam demonstrar a abrangência social da escrita indígena no âmbito reducional e quanto o vínculo existente entre escrita, poder e memória presidiram a decisão das lideranças indígenas em redigir mensagens. Enfim, o estudo das práticas letradas entre os guaranis das reduçôes fornece um exemplo das modificaçôes desencadeadas pela razão gráfica, efeitos irreversíveis, em uma população que durante séculos comunicou-se pela oralidade primária.

\section{Notas}

${ }^{1}$ GIBSON, Charles. Los aztecas bajo lo dominio español. México: Siglo XXI, 1967; LEON PORTILLA, Miguel. Visión de los vencidos: relatos indígenas de la conquista. México: Unam, 1976; GRUZINSKI, Serge. La colonización del imaginario. Sociedades indígenas y occidentalización en el México español. Siglos XVI-XVIII. México: FCE, 1991; LOCKHART, James. Los nahuas después de la Conquista. Historia social y cultural de la población indígena del México Central, siglos XVI-XVIII. México: FCE, 1999.

${ }^{2}$ MORINIGIO, Marcos. Sobre Cabildos indígenas de las Misiones. In: Revista de la Academia de Entre-Ríos. I, Nueva Impresora: Paraná, 1946, p.29-37; MELIÀ, Bartomeu. La création d'un langage chrétien dans les réductions des Guarani au Paraguay. 2 vols. Université de Strassbourg: Faculté de Théologie. Thesis, 1969;

Guarani del Paraguay: historia, sociedad y literatura. Madrid: Ed. Mapfre, 1992. 
${ }^{3}$ As primeiras produções textuais visavam à catequese, servindo de instrumento para a conversão. Nos séculos XVI e XVII, havia uma co-extensividade entre duas formas textuais, os catecismos e as gramáticas. As gramáticas, além de promover a codificação do guarani, estabelecendo novas categorias, proporcionavam à língua indígena um estatuto semelhante ao das línguas vernáculas. DAHER, Andréa. Écrire la langue indigène: la grammaire Tupi et les catéchismes bilingues au Brésil (XVI siècle). MÉLANGES de l'École Française de Rome. Italie et Mediterranée. Roma, v.111, no 1, p. 231-50, 1999.

${ }^{4}$ GOODY, Jack. A domesticação do pensamento selvagem. Lisboa: Editorial Presença, 1988.

${ }^{5}$ Entre estas duas formas de expressão comunicativa há uma tensão criativa recíproca, que por sua vez comporta uma dimensão histórica. As sociedades ocidentais, possuidoras de um sistema de escrita, estiveram permeadas, durante séculos, de diversos tipos de oralidade. Para uma aproximação a este tema, ver: GOODY, Jack. The interface between the written and the oral. Cambridge: Cambridge University Press, 1987; ZUMTHOR, Paul. A letra e a voz: a "literatura" medieval. São Paulo: Companhia das Letras, 1993; HAVELOCK, Eric. A musa aprende a escrever: reflexóes sobre a oralidade e a literacia da Antiguidade ao presente. Lisboa: Gradiva, 1996; FRENK, Margit. Entre la voz y el silencio: la lectura en tiempos de Cervantes. Alcalá de Henares: Centro de Estudios Cervantinos, 1997.

${ }^{6}$ ORUÉ POZZO, Aníbal. Oralidad y escritura en Paraguay: comunicación, antropologia e historia. Asunción: Arandurã: Universidad Autónoma de Asunción, 2002.

${ }^{7}$ ONG, Walter. Oralidade e cultura escrita: a tecnologização da palavra. Campinas: Papirus, 1988.

${ }^{8} \mathrm{O}$ que importa, de fato, como destacaram David Olson e Nancy Torrance, é o que as pessoas fazem com a escrita, e não o que a escrita faz com as pessoas. OLSON, D.R.; HILDYARD; A. TORRANCE, N. Literacy, language, and learning: the natural and consequences of reading and writing. Cambridge University Press, 1985, p. 14 apud OLSON, David R.; TORRANCE, Nancy (comp.). Cultura escrita y oralidad. Barcelona: Gedisa, 1995, p. 13.

${ }^{9}$ CERTEAU, Michel de. A invenção do cotidiano: 1. Artes de fazer. Petrópolis: Vozes, 1994.

${ }^{10}$ No século XVII, segundo uma das fontes da época, os guaranis já estavam exercitando sua instrução alfabética. Por meio do jesuíta Francisco Jarque, que compilou informações de outros religiosos, somos informados de que um cacique da redução de Loreto compôs Platicas y Sermones en su lengua e, uma vez concluída a redação dos sermôes, ofereceu aos padres seus textos. JARQUE, Francisco. Insignes misioneros de la Compañia de Jesús en la Provincia del Paraguay. Pamplona: Joan Micoan, 1687, p. 361.

${ }^{11}$ VILLAGRA-BATOUX, Delicia. El Guarani Paraguayo: de la oralidad a la lengua literaria. Asunción: Expolibro, 2002.

${ }^{12}$ KERN, Arno Alvarez. Missões: uma utopia política. Porto Alegre: Mercado Aberto, 1982 , p. 36.

13 Para uma descrição pormenorizada do perfil dos integrantes da elite missioneira e as tarefas desempenhadas, consultar: HAUBERT, Maxime. Índios e jesuitas no tempo das missões. São Paulo: Companhia das Letras, 1990, p. 223-32.

Topor, v. 8, n. 15, jul.-dez. 2007, p. 49-79. 
A Escrita dos guaranis NAS REdUÇões: USOS E FUNÇÕES DAS FORMAS TEXTUAIS INDÍGENAS - SÉCULO XVIII • 73

${ }^{14}$ Além da alfabetização e do convívio com a cultura escrita, os guaranis letrados manusearam, no primeiro quartel do século XVIII, uma máquina tipográfica nas reduções. $\mathrm{O}$ número de obras impressas nas reduçóes foi expressivo, totalizando 23 livros. PLA, Josefina. El barroco hispano-misioneiro. Asunción: Editorial del Centenário, 1975.

${ }^{15}$ NEUMANN, Eduardo S. Práticas letradas guaranis: produção e usos da escrita indígena (séculos XVII e XVIII). UFRJ (tese de doutorado), 2005.

${ }^{16}$ A possibilidade de localizar textos cuja autoria é indígena depende da procura paciente em meio a séries documentais relacionadas ao período. Os documentos escritos pelos jesuítas, como Tadeo Henis, Lourenzo Balda, Bernardo Nusdorffer, Luis Charlet, Juan de Escandón ou José Cardiel apresentam dados nesse sentido.

${ }^{17}$ Para uma aproximação a respeito da questão da escrita e sociedade, ver: BOUZA Alvarez, Fernando J. Del escribano a la biblioteca. La civilización escrita en la Alta Edad Média (siglos XV-XVII). Madrid: Síntesis,1992; CASTILLO, Antonio; SAEZ, Carlos. Paleografia versus alfabetización. Reflexiones sobre historia social de la cultura escrita. SIGNO. Revista de Historia de la Cultura Escrita. Universidad Alcalá de Henares n.1, p. 134-35, 1994; VIÑAO FRAGO, Antonio. Por una historia de la cultura escrita: observaciones y reflexiones. SIGNO. Revista de Historia de la Cultura Escrita. Universidad de Alcalá de Henares, n.3, p. 41-68, 1996; PETRUCCI, Armando. Alfabetismo, escritura, sociedad. Prólogo de Roger Chartier y Jean Hébran. Barcelona: Gedisa, 1999; PETRUCCI, Armando. La ciencia de la escritura: primera lección de paleografia. Buenos Aires: Fondo de Cultura Económica, 2002; CASTILLO GÓMEZ, Antonio (org.). Escribir y leer en el siglo de Cervantes. Barcelona: Gedisa, 1999. CASTILLO, GÓMEZ. (coord.). Historia de la cultura escrita. Del Próximo Oriente Antiguo a la sociedad informatizada. Gijón: TREA, 2002.

${ }^{18}$ A partir do reinado de Filipe II, o rei papeleiro, o Império espanhol foi gerenciado pelo mundo dos papéis. $\mathrm{O}$ uso da escrita, com eminente finalidade administrativa, estava "[...] produciendo una paulatina escriturización de la sociedad, en la que la escritura terminará por afectar de una forma u otra a capas cada vez más amplias de la población”. BOUZA, Alvarez. Imagen y propaganda: capitulos de historia cultural de Felipe II. Madrid: Akal, 1998, p. 40.

${ }^{19}$ Segundo Roger Chartier: "Da maior ou menor familiaridade com a escrita depende, pois, uma maior ou menor emancipação com relação a formas tradicionais de existência que ligam estritamente o indivíduo a sua comunidade, que o emergem num coletivo próximo, que o tornam dependente de mediadores obrigatórios, intérpretes e leitores da palavra divina ou das determinações do soberano." CHARTIER, Roger. As práticas da escrita. In: ARIÈS, Philipe; CHARTIER, Roger (org.). História da vida privada 3: da Renascença ao Século das Luzes. São Paulo: Companhia das Letras, 1991, p. 119.

${ }^{20}$ A produção escrita nas reduções geralmente foi atribuída ao trabalho dos escrivães: "Una gran parte del legado manuscrito en lengua guaraní salió de las manos de esos secretarios.” MELIÀ, Bartomeu. Op.cit. 1992, p. 137. 
${ }^{21}$ MELIÁ, Bartomeu. Un Guarani reportero de guerra. Acción, revista paraguaya de reflexión y dialogo. Asunción, no 208, p. 20-3, 2000.

${ }^{22}$ Arquivo Geral de Indias (A.G.I.) Sevilla. Audiencia de Buenos Aires, Legajo 42 [anexos da correspondência enviada à Espanha].

${ }^{23}$ Para uma introdução à temática da epistolografia na Idade Moderna, ver: SÁEZ SANCHEZ, Carlos; CASTILLO GÓMEZ, Antonio (ed.). La correspondencia en la historia: modelos y prácticas de la escritura epistolar. Madrid: Calumbur, 2000 (volume I: Actas del VI Congreso Internacional de Historia de la Cultura Escrita); A arte de escrever cartas: Anônimo de Bolonha, Erasmo de Rotterdam, Justo Lípsio / Emerson Tin (org.). Campinas, SP: Editora da Unicamp, 2005.

${ }^{24}$ CARBONELL de Masy, Rafael. Estrategia de desarrollo rural en los pueblos Guaranies (1609-1767). Barcelona: Instituto de Estudios Fiscales, 1992, p. 224.

${ }^{25}$ BLUMERS, Teresa. La contabilidad en las reducciones guaranies. Biblioteca Paraguaya de Antropologia, vol. 15. Centro de Estudios Antropológicos. Universidad Católica. Asunción, 1992.

${ }^{26}$ Arquivo Geral de Simancas (A.G.S.). Valladolid, Secretaría de Estado, Legajo 7425. Folios 145 y 146. Nesse arquivo há cópias traduzidas das cartas apreendidas com o cacique da redução de Yapeyu, Rafael Paracatu, logo após os incidentes no arroio do Daymal, em outubro de 1754. Os documentos foram traduzidos e uma cópia enviada por Thomas Hilson ao marquês de Valdelírios; Arquivo Histórico Nacional (A.H.N.). Madrid. Sección Clero-Jesuítas, Legajo 120, documento 54 (Relato de Escandón) 8-XI-1755. "Cogieronse le al Cacique Paracatu varios papeles y cartas escritas en su propia lengua. $\mathrm{Y}$ ante todas cosas mucha prudencia rúbrico de propia mano el governador y luego las mandó traducir para saber lo que contenia”, p. 114.

${ }^{27}$ A.G.S., Secretaría de Estado. Legajo 7425.

${ }^{28}$ A.H.N. Sección Clero-Jesuítas, Legajo 120. "RELACIÓN de lo que succedio a 53 Indios del Uruguay, cuando acometieron por $2^{\circ}$ con otros muchos el fuerte de los Portugueses del Rio Pardo, escribio un Indio Luisista que fue uno de estos 53 llamado Chrisanto, de edad como de 40 años, Indio Capax y mayordomo del pueblo, traduxo lo un misionero de la Lengua Guarani en castellano, año 1755".

${ }^{29}$ Real Academia de la Historia. Madri (RAH). Sobre el tratado con Portugal. P. Manuel Quirino; 9-11-5-151; sig 9/2279, Mss. p. 184v.

${ }^{30}$ CASTILLO GÓMEZ, Antonio. La fortuna de lo escrito: funciones y espacios de la razón gráfica (siglos XV-XVII). Bulletin Hispanique. Bordeaux, t.100, no 2, p. 343-81, 1998 (p. 354).

${ }^{31}$ AMELANG, James. El vuelo de Ícaro: la autobiografia popular en la Europa moderna. Madrid: Siglo Veintiuno Editores, 2003, p. 17-8.

${ }^{32}$ A.G.S., Secretaria de Estado. Legajo 7410.

${ }^{33}$ Archivo General de Índias (A.G.I.). Sevilla. Audiencia de Buenos Aires, 42. Carta de Pasqual Yaguapo a Miguel Arayecha. 22 de octubro de 1754. Copia N 7. Es copia que 
A Escrita dos guaranis NAS REduÇões: USOS E FUNÇÕES DAS FORMAS TEXTUAIS INDÍGENAS - SÉCULO XVIII • 75

concuera con la traducción original que queda en la secretaria de mi cargo. Campamento em el Arroyo Ybacacay Marzo 8 de 1756. Pedro Medrano.

${ }^{34}$ A.G.S. Secretaria de Estado, Legajo 7410, documento número 6. "Una copia en quatro foxas de un papel sin fecha con una firma que dice: Hixos de San Francisco de Borxa. Y a continuación va outra Copia de una carta que parece escrita por Pascual Yaguapo a Joseph Tiarayu, los dos naturales del Pueblo de San Miguel en 16 de Junio del año pasado de 1755."

${ }^{35}$ A. H.N. Clero-Jesuítas, legajo 120, caja 2, doc. 75. Valentin Barigua: "Entre los indios si que ay tal nombre, y apellido; que lo es de una de las principales familias del Pueblo de S. Miguel [...] Este indio pues, que entonces era Mayordomo del dicho Pueblo, es de quien estaba escrita, y firmada la carta. (...)” p. 25.

${ }^{36}$ Relação abreviada da republica que os religiosos das provincias de Portugal e Hespanha, estabelecerão nos Domínios Ultramarinos das duas Monarchias. Lisboa, 1757; PASTELLS, tomo VIII, doc. 4.758, 1949, p. 243.

${ }^{37}$ Arquivo Geral da Nação (A.G.N.). Buenos Aires. Sala IX, legajo IX, 6, 10,7. Carta do Teniente. Don Valentin Ybariguá al gobernador Zavala. São Miguel 12 de agosto de 1768 (Tradução Delicia Villagra).

${ }^{38}$ A.G.N. Sala IX, Legajo IX, 6, 10,7. "Carta do teniente Don Valentin Ybarigua al Sr Gobernador Francisco Bucareli.” São Miguel, 13 de agosto de 1768 (tradução Angelica Otazú).

39 A "Compulsa" orientava quanto aos procedimentos a serem adotados, por parte das autoridades coloniais, no momento de realizar o inventário dos bens deixados nas reduções em decorrência da expulsão da Companhia de Jesus dos domínios hispano-americanos, em 1768. No seu preâmbulo, especificava que para esse documento ser validado deveriam estar presentes "alguns indivíduos del cavildo". Entre os guaranis presentes que subscreveram tal compulsa figurava o nome do então tenente Valentin Ybariguá.

\section{Referências bibliográficas}

A arte de escrever cartas: Anônimo de Bolonha, Erasmo de Rotterdam, Justo Lípsio / Emerson Tin (org.). Campinas, SP: Editora da Unicamp, 2005.

AMELANG, James. El vuelo de Ícaro: la autobiografia popular en la Europa moderna. Madrid: Siglo Veintiuno Editores, 2003.

BLUMERS, Teresa. La contabilidad en las reducciones guaranies. Asunción: Universidad Católica, 1992.

BOUZA ÁLVAREZ, Fernando J. Del escribano a la biblioteca. La civilización escrita en la Alta Edad Média (siglos XV-XVII). Madrid: Síntesis, 1992.

. Imagen y propaganda: capitulos de historia cultural del reinado de Felipe II. Madrid: Akal, 1998.

CARBONELL DE MASY, Rafael. Estrategia de desarrollo rural en los pueblos 
Guaranies (1609-1767). Barcelona: Instituto de Estudios Fiscales, 1992.

CASTILLO GÓMEZ, Antonio. La fortuna de lo escrito: funciones y espacios de la razón gráfica (siglos XV-XVII). Bulletin Hispanique. Bordeaux, t.100, no 2, p. 343-81, 1998.

(org.). Escribir y leer en el siglo de Cervantes. Barcelona: Gedisa, 1999. . Entre publiqué et privé: strategies de l'écrit dans l'Espagne du Siècle d'or. Annales: Histoire, Sciences Sociales. Paris, nº 4-5, p. 803-29, jul./oct. 2001. (coord.). Historia de la cultura escrita. Del Próximo Oriente Antiguo a la sociedad informatizada. Gijón: TREA, 2002.

CERTEAU, Michel de. A invenção do cotidiano: 1. Artes de fazer. Petrópolis: Vozes, 1994.

CHARTIER, Roger. As práticas da escrita. In: ARIÈS, Philipe; CHARTIER, Roger (org.). História da vida privada 3: da Renascença ao Século das Luzes. São Paulo: Companhia das Letras, 1991, p. 113-62.

DAHER, Andréa. Écrire la langue indigène: la grammaire Tupi et les catéchismes bilingues au Brésil (XVI siècle). Mélanges de l'École Française de Rome. Italie et Mediterranée, Roma, v.111, no 1, p. 231-50, 1999.

FRENK, Margit. Entre la voz y el silencio: la lectura en tiempos de Cervantes. Alcalá de Henares: Centro de Estudios Cervantinos, 1997.

GIBSON, Charles. Los aztecas bajo lo dominio español. México: Siglo Veintiuno Editores, 1967.

GOODY, Jack. The interface between the written and the oral. Cambridge: Cambridge University Press, 1987.

. A domesticação do pensamento selvagem. Lisboa: Editorial Presença, 1988.

GOLIN, Tau. A guerra guaranitica: como os exércitos de Portugal e Espanha destruiram os Sete Povos dos jesuitas e indios guaranis no Rio Grande do Sul (17501761). Passo Fundo: Ediupf; Porto Alegre: EDUFRGS, 1998.

GRUZINSKI, Serge. La pensée metisse. Paris: Fayard, 1999.

. La colonización de lo imaginario. Sociedades indígenas y occidentalización en el México español. Siglos XVI-XVIII. México: FCE, 1991.

HAUBERT, Maxime. Índios e jesuitas no tempo das missóes - séculos XVII e XVIII. São Paulo: Companhia das Letras: Círculo do Livro, 1992.

HAVELOCK, Eric. A musa aprende a escrever: reflexōes sobre a oralidade e a literacia da Antiguidade ao presente. Lisboa: Gradiva, 1996. 
A Escrita dos guaranis NAS REdUÇões: USOS E FUNÇÕES DAS FORMAS TEXTUAIS INDÍGENAS - SÉCULO XVIII • 77

JARQUE, Francisco. Insignes misioneros de la Compañia de Jesús en la Provincia del Paraguay. Pamplona: Joan Micoan, 1687.

KERN, Arno Alvarez. Missóes: uma utopia política. Porto Alegre: Mercado Aberto, 1982.

LEON PORTILLA, Miguel. Visión de los vencidos: relatos indígenas de la conquista. México: Unam, 1976.

LOCKHART, James. Los nahuas después de la Conquista. Historia social y cultural de la población indígena del México central, siglos XVI-XVIII. México: FCE, 1999.

MELIÁ, Bartomeu. La création d'un langage chrétien dans les réductions des Guarani au Paraguay. 2 vols. Université de Strassbourg: Faculté de Théologie. Thesis, 1969.

. La lengua Guarani del Paraguay: historia, sociedad y literatura. Madrid: Mapfre, 1992.

. Un Guaraní reportero de guerra. Acción. Revista paraguaya de reflexión y diálogo, 208, p. 20-3, 2000.

MORINIGIO, Marcos. Sobre los cabildos indígenas de las misiones. Revista de la Academia de Entre Ríos, I, p. 29-37, 1946.

NEUMANN, Eduardo S. Práticas letradas guarani: produção e usos da escrita indígena (séculos XVII e XVIII). UFRJ (tese de doutorado), 2005.

OLSON, D.R.; HILDYARD, A.; TORRANCE, N. Literacy, language, and learning: the natural and consequences of reading and writing. Cambridge University Press, 1985.

ONG, Walter. Oralidade e cultura escrita: a tecnologização da palavra. Campinas: Papirus, 1988.

ORUÉ POZZO, Anibal. Oralidad y escritura en Paraguay: comunicación, antropología e historia. Asunción: Arandurã, 2002.

PASTELLS, Pablo; MATEOS, Francisco. Historia de la Compañia de Jesús en la Provincia del Paraguay (Argentina, Paraguay, Uruguay, Peru, Bolivia y Brasil): según los documentos originales del Archivo General de Indias. Tomo VIII. S.J. Madrid: Librería General de Victoriano Suarez: C.S.I.C., 1949.

PETRUCCI, Armando. Alfabetismo, escritura, sociedad. Prólogo de Roger Chartier y Jean Hébran. Barcelona: Gedisa, 1999.

. La ciencia de la escritura: primera lección de paleografia. Buenos Aires: Fondo de Cultura Económica, 2002.

PLA, Josefina. El barroco hispano-misioneiro. Asunción: Editorial del Centenário, 1975.

RELAÇÃO abreviada da república que os religiosos das províncias de Portugal 
e Hespanha, estabelecerão nos Domínios Ultramarinos das duas Monarchias. E da guerra, que neles tem movido, e sustentado contra os Exércitos Hespanholes, e portuguezes; e por outros documentos authenticos. Lisboa: [s.n.], 1757.

SÁEZ SANCHEZ, Carlos; CASTILLO GÓMEZ, Antonio. Paleografia versus alfabetización. Reflexiones sobre historia social de la cultura escrita. SIGNO. Revista de Historia de la Cultura Escrita. Universidad Alcalá de Henares. ํํ1, p. 134-35, 1994.

(ed.). La correspondencia en la historia: modelos y prácticas de la escritura epistolar. Madrid: Calumbur, 2000 (volume I: Actas del VI Congreso Internacional de Historia de la Cultura Escrita).

SANTOS, Julio Ricardo Quevedo. Guerreiros e jesuitas na utopia do Prata. Bauru: Edusc, 2000.

VILLAGRA-BATOUX, Sara Delicia. El Guarani Paraguayo: de la oralidad a la lengua literaria. Asunción: Expolibro, 2002.

VIÑAO FRAGO, Antonio. Por una historia de la cultura escrita: observaciones y reflexiones. SIGNO. Revista de Historia de la Cultura Escrita. Universidad de Alcalá de Henares, no 3, p. 41-68, 1996.

ZUMTHOR, Paul. A letra e a voz: a "literatura" medieval. São Paulo: Companhia das Letras, 1993.

\section{RESUMO}

O uso da escrita por parte dos guaranis foi intenso a partir da celebração do Tratado de Madri, em 1750. Diante da permuta de territórios sul-americanos, por parte das monarquias ibéricas, os indígenas alfabetizados das reduçôes destinaram à prática da escrita novas finalidades. Nessa ocasiāo, os contatos epistolares foram muito valorizados pelos guaranis.

A decisão indígena de manifestar por escrito suas opiniōes expressa por um lado a importância conferida às negociaçôes in scriptis e, por outro, o conhecimento das práticas administrativas vigentes no Império espanhol. No século XVIII, os guaranis letrados escreveram com freqüência e, por vezes, com maior desenvoltura do que os colonizadores hispano-americanos.

Palavras-chave: indios guaranis, reduçoes, formas textuais indígenas. 
A ESCRITA DOS GUARANIS NAS REDUÇÕES: USOS E FUNÇÕES DAS FORMAS TEXTUAIS INDÍGENAS - SÉCULO XVIII • 79

\section{ABSTRACT}

The use of writing by the Guarani Indians was stressed after the Treaty of Madrid, in the year 1750. In the face of the South American territory exchange by the monarchies of Iberia, the literate Indians of the missions gave new applications to the use of writing. In this occasion, the epistolary contacts were truly valued by the Guarani Indians.

The indigenous decision express their opinions in the written language expresses, on one hand, the importance in script negotiations had, and on the other, the knowledge of the administrative practices of the Spanish Empire. In the XVIII century, the literate Guarani Indians wrote frequently and, sometimes, even more skillfully than the Spanish American settlers.

Keywords: Guarani Indians, missions, indigenous textual forms.

Recebido em junho de 2006 e aprovado em maio de 2007 